title indicates, among other things, an introductory text suitable not just for psychiatrists but also for physiological psychology courses, and rather different from McCleary and Moore. The revision is chiefly addition of passages to the ends of some chapters (not always related to the original text). A separate list of review articles-a feature of the original edition useful in an introductory text - has disappeared. Curiously, the bibliography does not include Smythies, 1957 or 1963, cited in the text. Naturally, another author might have included or excluded some experiments or theories Smythies has not, especially if writing now, rather than two years ago. But, in my opinion, the treatment seems judicious and broadly up to date, and pleasingly detailed for an overall picture in so brief a compass.

One may doubt that all psychological explanations of normal human learning and thought must eventually be superseded by more powerful physiological explanations-making sense of otherwise arbitrary details of the microscopic workings of the brain is likely to require reference to functional control. Yet even if that is so, it is important to press on in the direction of Smythies's concluding "psychiatric speculations", and make them testable as he hopes. $\mathrm{He}$ suggests that in normal behaviour the limbic system selects ideation (and perhaps perception) according to emotional and motivational relevance. Then in endogenous depression and in schizophrenia, the limbic system may mediate the generation by affect of unrealistic thought and experience, respectively. Explaining cerebral control of behaviour is more than merely an intellectual challenge, daunting though that is.

D. A. Boorh

\section{Biology of Land Slugs}

Terrestrial Slugs. By N. W. Runham and P. J. Hunter. Pp. 184. (Hutchinson: London, January 1971.) $40 s$ boards; $16 s$ paper.

Terrestrial Slugs is a volume in the Hutchinson's University Library series. It is clearly printed, easily read, and is superior to some of its companion volumes, for it has a comprehensive, modern and easily used literature list with the full titles of the references. It has also a considerable number of illustrations, but these are of a variable quality. In the preface the authors write that the book might "promote the use of slugs in schools and universities for research and teaching". It may well succeed in doing this, for certain chapters such as those on "Food", "Metabolism", and "Slugs as Pests" review the available information clearly and simply and so make a definite contribution to the subject.

The other group for whom the book is intended are "people seeking to control ... these pests" who might then produce "more effective chemical and biological control methods". This group is less well served for following this idealism one might expect after concluding in chapter 8 that biological control is at the present time impractical, the authors would then give a comprehensive review of the topic to preserve the balance of the book. In fact, biological control is dismissed in 100 words as an academic bauble and even slug predators have only about 400 words in the ecology section. The section on chemical control has ten times more space, and although this may reflect current thinking among those engaged in chemical control, I suspect that this may be changing quicker than the authors appreciate.

Certain topics like microhabitats, micrometeorology and a key to the mere twenty-six British species are not included and others, like taxonomy, genetics and behaviour, could either be expanded or improved. The ecology section, around which the whole book could have pivoted, is somewhat parochial in approach and is opened by a section on sampling methods where the usual distinction between mechanical and behavioural extraction techniques is not made. I found the authors provocative in the section on population regulation and not too helpful to the lay reader (at whom the book is aimed) who would require references to both Wynne-Edwards and Solomon. The authors do not review ecological energetics because "this ... study does not help us to understand the distribution of a single species, or how the numbers are regulated" (p. 129). This valuable modern approach, which has given ecologists their first opportunity to evaluate the components of an ecosystem, is thus dismissed for not supplying the answers to questions not asked of it.

This book succeeds in surveying most aspects of the modern work on slug biology. It is a work of honest endeavour but proof reading errors and inaccuracies in the text leave scope for improvement in a subsequent edition.

Peter F. NeWell

\section{African Beetles}

Monograph of the Praeugenina. (Coleoptera: Tenebrionidae: Strongyliini.) By P. P. de Moor. Pp. vii $+203+8$ plates and 8 maps. (The Transvaal $\mathrm{Mu}$ seum: Pretoria, 1970.)

DESPITE the richness and singularity of the beetle fauna of Ethiopian Africa, comprehensive studies of the African fauna in particular groups of Coleoptera are still very few. The very large family Tenebrionidae has been studied in South Africa by C. Koch, who died after producing only one volume of a projected series on the South African representatives of the family; P. P. de Moor now seems to be carrying on his tradition in the Transvaal Museum, who are to be congratulated on this excellently produced publication.

The Praeugenina are limited to Africa and Madagascar, and comprise eleven currently recognized genera, five of which are confined to Madagascar and not treated in detail in this work; one of the six African genera, already monographed by Gridelli, is also not dealt with beyond inclusion in the key to genera. Five genera and some 107 species are fully characterized and illustrated by figures of whole beetles and aedeagi. As pointed out by de Moor, nothing has yet been recorded about the larvae, habitats and habits of any of the species, beyond the fact that most specimens in museum collections have been taken at lights.

In defining the group, de Moor says "The presence of a stridulatory gula distinguishes the subtribe Praeugenina from all other tribes of Tenebrioid Tenebrionidae ... excepting the Platynotini and Oncotini". This statement is incorrect, or at least misleading, as stridulatory files on the gula are found also in Helops spp., Gnathocerus, and some Hypophloeinae. He also draws attention to an additional character distinguishing Strongyliini from Tenebrionini, in the presence of a semi-transparent and partly sclerotized membrane fused to the anterior edge of the clypeus, and comments on the placings of a number of genera.

The author deals very briefly with "Distribution and Phylogenetic Considerations", saying "In view of the lack of knowledge regarding all but the superficial anatomy, not only of this group but of the entire subfamily Strongyliinae, it seems unwise at present to speculate on phylogenetic relationships", and is content to produce what the numerical taxonomists would call phonetically based groupings. This is not likely to detract from the immediate usefulness of his work.

In sum, this work represents a very useful and promising beginning; to treat the entire family Tenebrionidae of Africa alone on the scale set by $\mathrm{Mr}$ de Moor in this book would require thirty or more similar sized volumes, and might well occupy him for more than a lifetime. Meanwhile, there might be a case for the production of works dealing with larger groupings in a less thorough and detailed way, perhaps on the model of Schedl's on African Scolytidae. R. A. Crowson 